\title{
UTILIZACIÓN DEL AULA VIRTUAL POR DOCENTES DE LA FACULTAD DE CIENCIAS CONTABLES (2014)
}

\author{
USING THE VIRTUAL CLASSROOM BY TEACHERS OF \\ THE SCHOOL OF ACCOUNTING (2014) \\ Jorge Raúl CARreño Escobedo * \\ Docente Auxiliar de la Facultad de Ciencias Contables \\ Universidad Nacional Mayor de San Marcos - UNMSM / Lima - Perú \\ [Recepción: Setiembre de 2015/ Conformidad: Octubre 2015]
}

\section{RESUMEN}

Los medios electrónicos de aprendizaje se están convirtiendo en el medio más común utilizado por muchas instituciones educativas a nivel nacional e internacional.

Es por ello que, en algunas de las facultades de la Universidad Nacional Mayor de San Marcos, vienen aprovechando el uso del aula virtual; como es el caso, la facultad de Ciencias Contables desde hace algunos años viene utilizando y aprovechando el recurso de aprendizaje por Internet. Esta herramienta de virtualización, llamada Moodle 2.5 permite que tanto docentes como estudiantes, y otros invitados accedan a recibir la enseñanza virtual.

Ante tal usabilidad del recurso de aprendizaje e-learning (por Internet), se pone de manifiesto la eficiencia en el uso del aula virtual por los docentes de la facultad de Ciencias Contables a setiembre de 2014, a través de ciertos criterios.

La población tomada fue en base a 105 docentes, de la cual se tomó como muestra a 30 docentes que asistieron regularmente al curso de capacitación en aula virtual: Herramientas para la docencia universitaria.

\section{Palabras clave:}

Uso de aula virtual; eficiencia académica; Moodle; aprendizaje e-learning; aprendizaje a distancia; curso virtual.

\begin{abstract}
Electronic media learning are becoming the most common means used by many educational institutions nationally and internationally.

For that reason, some of the faculties of the National University of San Marcos are taking advantage of the virtual classroom use; in that case, the School of Accounting has been using and benefitting from the online learning resource for some years. This virtualization tool called Moodle 2.5 allows both teachers and students, and other guests to receive access to e-learning.

Given the resource utility of e-learning (online), it evidenced the efficiency of the virtual classroom by teachers of the School of Accounting Sciences in September 2014, through certain criteria.

The population considered was based on 105 teachers where a group of 30 teachers was sampled, they regularly attended the training course in Virtual Classroom: Tools for university teaching.
\end{abstract}

\section{Keywords:}

Virtual class use; academic efficiency; Moodle; e-learning; distance learning; virtual course.

\footnotetext{
* Ingeniero de Sistemas -Universidad César Vallejo. Colegiado. Email: jcarrenoe@unmsm.edu.pe
} 


\section{INTRODUCCIÓN}

Actualmente, en el modelo de aprendizaje de la educación superior en la UNMSM, ya se tiene el soporte tecnológico del aula virtual como herramienta de fácil acceso en la organización de un curso presencial. Esta forma de aprendizaje es un buen complemento para la enseñanza.

El Modelo Educativo San Marcos, (UNMSM, 2013) señala que "como parte del proceso de aprender a aprender y aprendizaje autónomo, las Tecnologías de la Información y Comunicación (TIC) han adquirido vital importancia en el sistema universitario. Las universidades usan las TIC de forma sistemática en sus funciones de creación, transmisión y almacenamiento de la información, en sus procesos de investigación y formación de profesionales".

En este aspecto, hay nuevas demandas que están en crecimiento, destacándose la formación virtual, formación continua y formación de posgrado.

Siendo un mundo cambiante el que se vive hoy en día, la facultad de Ciencias Contables va entrando en el mundo de la virtualización (Santibáñez, 2010). Es por ello, que el siguiente artículo busca encontrar la eficiencia en el uso del aula virtual por los docentes de la facultad de Ciencias Contables en 2014.

La facultad de Ciencias Contables de la UNMSM cuenta con 105 docentes, de los cuales 30 se capacitaron en forma presencial y virtual durante los meses de enero a marzo de 2014 para el desarrollo de su aula virtual utilizando la plataforma educativa Moodle 2.52, materiales educativos en físico y en línea, videos tutoriales y links de interactividad a los programas de mayor uso: Teachertube, Prezi, Microsoft.

\section{EVALUACIÓN DE INTERACCIÓN CON LAS ACTIVIDADES DEL DOCENTE EN EL AULA VIRTUAL}

Como parte de la dinámica de interacción del docente con el aula virtual, se consideró las calificaciones vigesimales, con nota 20 (veinte) como máximo a las siguientes actividades (Silva J., 2011):

1. Uso del aula virtual.- El aula virtual reporta el tiempo que el usuario estudiante o docente tiene dentro del mismo, por lo que se podrá constatar con la estadística que es para todo el grupo de estudio. De esta muestra, se tuvo a 21 usuarios que hicieron uso del aula virtual.

2. Materiales en su curso virtual .- Se considera que el docente de su curso virtual pueda subir materiales, en este caso y para efectos de práctica, aún no se consideró la calidad del material, sino más bien, la interacción con el reconocimiento de las herramientas virtuales: Moodle 2.5. Se obtuvo como resultado a 17 docentes que subieron materiales en su curso del aula virtual. (Munday, 2004). Para esta capacitación el moderador, entregó a los docentes, videos tutoriales asi como, un manual completo del uso del aula virtual, por lo que le serviría para consultas in situ o posteriores.

3. Foro de discusión.- El docente pudo interactuar en tiempo real dentro del espacio virtual para compartir con sus demás compañeros acerca de distintas opiniones. El promedio de calificaciones de este ítem foro de discusión es de 17.1 de nota.

4. Foro de debate.- Se planteó un tema a los docentes, quienes pudieron debatir acerca del mismo, el tema fue planteado por el moderador del grupo de capacitación. El promedio de calificaciones de este ítem foro de debate es de 17.1 de nota.

Los foros de discusión y foros de debate se pueden resumir como:

- Un espacio social para que los docentes se conozcan.

- Para los avisos del curso (usando un foro de noticias con suscripción forzada).

- Para discutir el contenido del curso o de materiales de lectura.

- Para continuar en línea una cuestión planteada previamente en una sesión presencial.

- Para discusiones solo entre profesores del curso (mediante un foro oculto).

- Un centro de ayuda donde los tutores y los docentes pueden dar consejos.

- Un área de soporte uno-a-uno para comunicaciones entre alumno y profesor (usando un foro con grupos separados y con un docente por grupo). 
- Para actividades complementarias, como "lluvia de ideas" donde los docentes puedan reflexionar y proponer ideas.

5. Tarea 1.- Se les dejó una primera tarea al docente para que pueda realizarla en el aula virtual. El promedio calificativo del grupo en Tarea 1 , fue de 16.7 de nota. (Baños, 2007).

6. Tarea 2.- Complementar la utilización del recurso "tarea", para así orientar el docente a sus alumnos. El promedio calificativo del grupo en Tarea 2, fue de 16.7 de nota igual que la Tarea 1 .

Acerca de la actividad tarea, se puede decir que:

- El módulo de Tareas permite a un profesor evaluar el aprendizaje de los alumnos mediante la creación de una tarea a realizar que luego revisará, valorará y calificará.

- Los alumnos pueden presentar cualquier contenido digital (archivos), como documentos de texto, hojas de cálculo, imágenes, audio y vídeos entre otros. Alternativamente, o como complemento, la tarea puede requerir que los estudiantes escriban texto directamente en un campo utilizando el editor de texto.

- Una tarea también puede ser utilizada para recordar a los estudiantes actividades del "mundo real" que necesitan realizar y que no, requieren la entrega de ningún tipo de contenido digital.

- Al revisar las tareas, los profesores pueden dejar comentarios de retroalimentación y subir archivos, tales como: anotaciones a los envíos de los estudiantes, documentos con observaciones o comentarios en audio.

- Las tareas pueden ser calificadas según una escala numérica o una escala personalizada, o bien, mediante un método de calificación avanzada, como una rúbrica. Las notas finales se registran en el libro de calificaciones.

\section{EVALUACIÓN DEL CONTENIDO DE CADA CURSO DE LOS DOCENTES}

Además, se consideró los criterios a evaluar a cada docente dentro de su curso virtual creado a cada uno, para que puedan desarrollarse mejor e individualmente. Estos criterios se registraron con puntaje vigesimal, con nota máxima de 20 (veinte) puntos.

Estos criterios son los siguientes (Rodriguez, 2005):

1. Ética.- Se consideró que cada docente debió dar crédito a quien le corresponda, el material e información que ha subido a su curso para ser visto por sus alumnos debe ser propicio. El promedio de la muestra del criterio de Ética fue de 12.4 puntos de nota. (Torras, 2013)

2. Presentación.- De la actividad elegida del sílabo con los criterios de la metodología de Aprendizaje Basado en Problemas (ABP), el docente debió armar su curso con las indicaciones dadas para causar impacto en sus estudiantes. El promedio de la muestra de este criterio fue de 11.7 puntos de nota.

3. Organización.- De los tres momentos de la actividad: planificación, ejecución y evaluación, el docente deberá ubicar su material para ser visto por el estudiante, de manera ordenada y entendible. El promedio de la muestra de este criterio fue de 11.7 puntos de nota.

4. Contenido.- El docente debe subir al aula virtual su material gradualmente o no, de acuerdo al avance curricular del sílabo, para que sus alumnos lo estudien. El promedio de la muestra de este criterio fue de 12.4 puntos de nota.

\section{RESULTADOS}

Los docentes de la facultad de Ciencias Contables desarrollaron 30 cursos en el aula virtual a cargo de dos moderadores que lo dictaron. El uso eficiente estuvo comprendido por 21 cursos en el aula con la plataforma Moodle. El ratio de capacitación es de 5 docentes para el uso eficiente de un aula virtual. 
Los docentes que trabajaron su curso en el aula virtual durante la clase presencial, obtuvieron mayor puntaje que los docentes que realizaron sus actividades como tarea remota para casa desde un punto con Internet fuera del campus universitario.
De la muestra, se pudo obtener como resultado que 09 docentes, elaboraron mejor su trabajo en el aula virtual estando in situ, pero no remotamente cuando se le dejó trabajo de casa.

\section{Gráfico $\mathrm{N}^{\circ} 01$}

Promedio de evaluación de interacción con las actividades del docente en el aula virtual

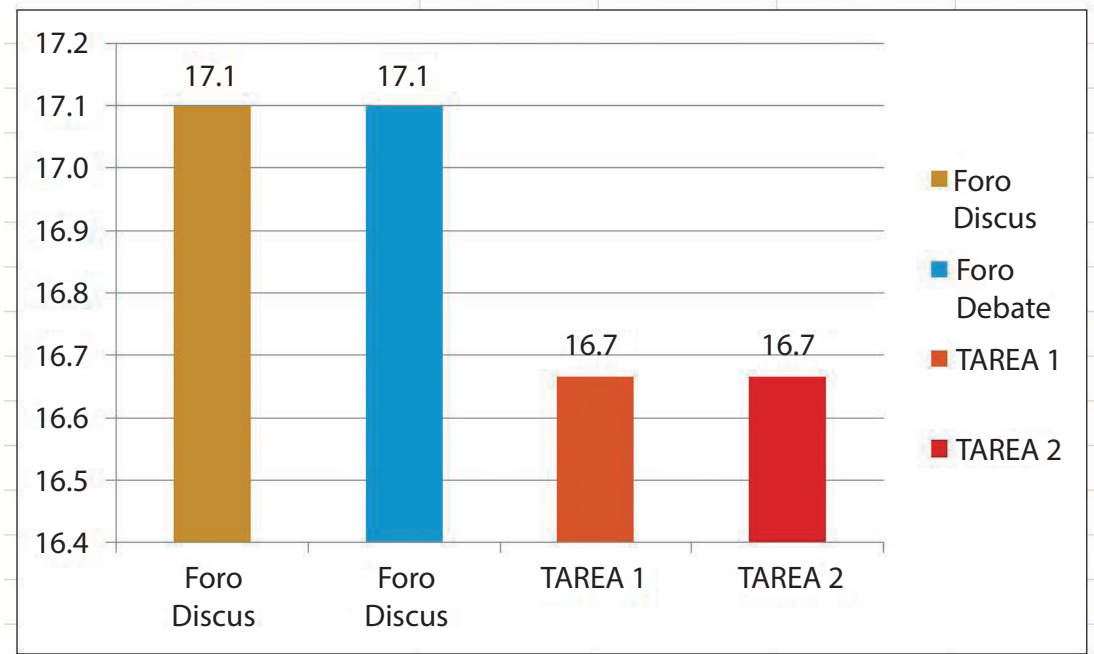

Fuente: Elaboración propia.

La "Evaluación de interacción con las actividades del docente en el aula virtual", fue realizada dentro del horario de clases, por lo que el docente lo cumplió satisfactoriamente.
De esta interacción en el aula virtual, sumado con los criterios, se obtuvo el nivel de eficiencia de uso del aula virtual por parte de los docentes de la facultad de Ciencias Contables de la UNMSM.

\section{Gráfico $\mathrm{N}^{\circ} 02$}

Promedio de evaluación del contenido de cada curso de los docentes

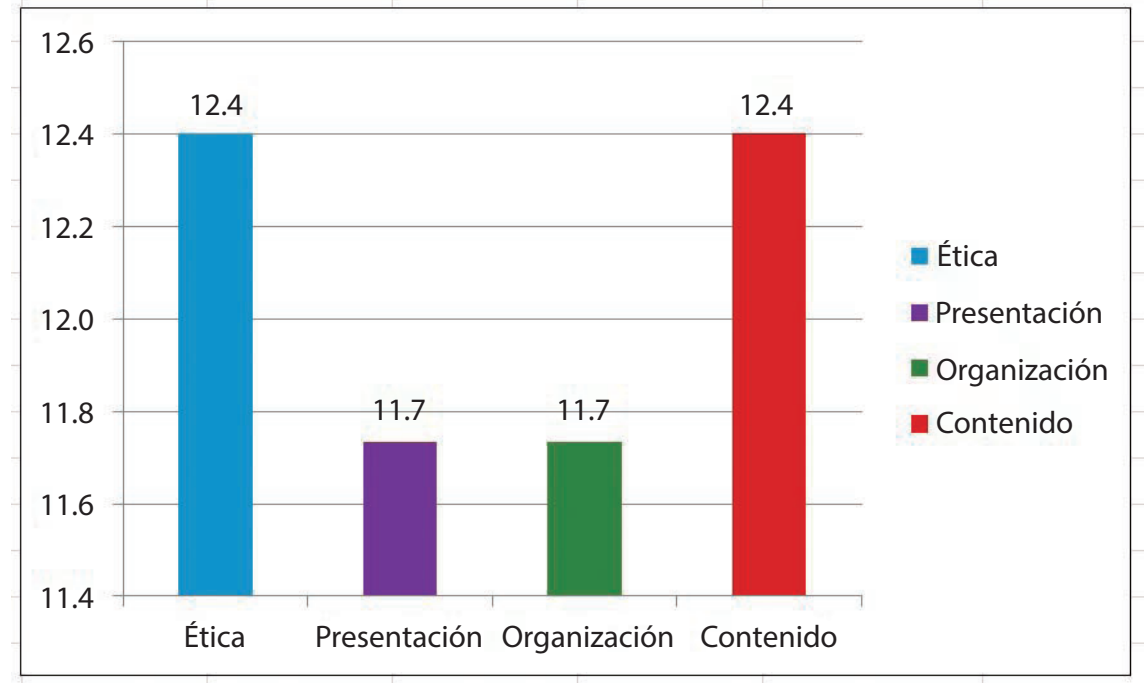

Fuente: Elaboración propia. 
La "Evaluación del contenido de cada curso de los docentes", fue realizada fuera del horario de clases, por lo que el docente cumplió en una proporción de $2 / 3$ aproximadamente del total de participantes.

Se puede notar por las cifras presentadas en las imágenes, que los docentes trabajaron mejor estando dentro del campus y con la guía del moderador, obteniéndose en el foro de discusión como promedio general 17.1 que equivale al $85.5 \%$ de eficiencia. En el foro de debate se obtuvo como promedio general 17.1 que equivale al $85.5 \%$ de eficiencia, similar al del foro de discusión.
En la Tarea 1 y Tarea 2 se obtuvieron un promedio de 16.7 que equivale al $83.3 \%$ de eficiencia. En el criterio de Ética se obtuvo 12.4 de promedio, que equivale al $62 \%$ de manera remota. En el criterio de presentación se obtuvo 11.7 de promedio, que equivale al $58.7 \%$ de manera remota. En el criterio de organización se obtuvo 11.7 de promedio, que equivale al $58.7 \%$ de manera remota. En el criterio de Contenido se obtuvo 12.4 de promedio, que equivale al $62 \%$ de manera remota.

\section{Gráfico $\mathrm{N}^{\circ} 03$}

Uso regular del aula virtual docentes facultad de Ciencias Contables - UNMSM

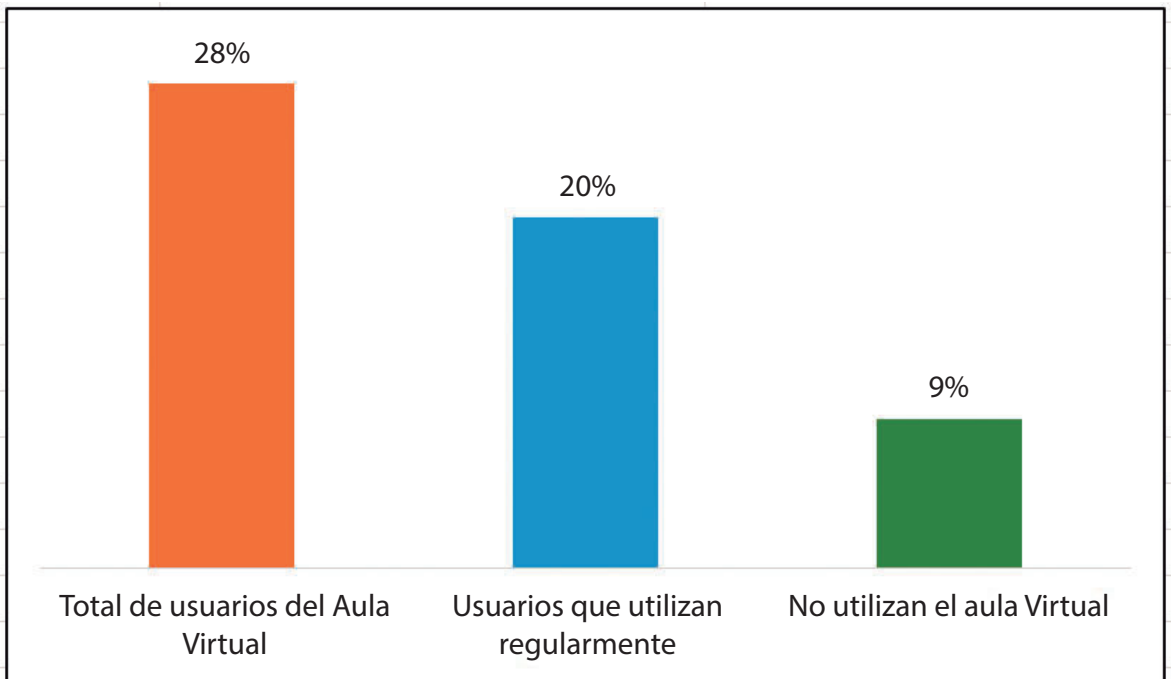

Fuente: Elaboración propia.

La preparación de un curso en el aula virtual es un medio de apoyo a la clase presencial, tanto para las tareas, comunicaciones, controles de lectura y evaluaciones en líneas, previas al examen presencial.

Los docentes de la facultad de Ciencias Contables que vienen utilizando el aula virtual, se encuentran con mayor apoyo en el uso de la tecnología, debiéndose tener en consideración que la ética es un factor importante para subir el material en el aula virtual, reconociendo la fuente original de autores sobre algún trabajo que sea utilizado como material de aprendizaje.
Se evidencian los resultados para la facultad de Ciencias Contables, con la aplicación de los criterios antes mencionados para su calificación. Dicha calificación con la que se aprobó ha sido mayor o igual que 10.5 para cada curso de cada docente.

Cuanto mayor es la cantidad de cursos en el aula virtual, mayor ha sido la interacción y menor el costo de papel y de documentación física.

Para el docente ha sido de mayor oportunidad obtener toda la documentación las veces que sean necesarias, utilizando el aula virtual, ya que les ha permitido monitorearlas desde la plataforma virtual. 


\section{CONCLUSIONES}

1. El ratio de eficiencia en la usabilidad del aula virtual en Moodle se ha realizado con los docentes de la facultad de Ciencias Contables de la UNMSM que asistieron a la capacitación y que implementaron su (s) curso (s) de forma completa.

2. Se puede concluir por las cifras presentadas, que los docentes trabajaron mejor, encontrándose dentro del campus universitario y con la guía del moderador, obteniéndose en el foro de discusión como promedio general 17.1 que equivale al $85.5 \%$ de eficiencia. En el foro de debate se obtuvo como promedio general 17.1 que equivale al $85.5 \%$ de eficiencia, similar al del foro de discusión.

3. En la Tarea 1 y Tarea 2 se obtuvieron un promedio de 16.7 que equivale al $83.3 \%$ de eficiencia. En el criterio de Ética se obtuvo 12.4 de promedio, que equivale al $62 \%$ de manera remota. En el criterio de presentación se obtuvo 11.7 de promedio, que equivale al $58.7 \%$ de manera remota. En el criterio de organización se obtuvo 11.7 de promedio, que equivale al $58.7 \%$ de manera remota. En el criterio de Contenido se obtuvo 12.4 de promedio, que equivale al $62 \%$ de manera remota.

4. Se evidencia que los docentes de la facultad de Ciencias Contables de la UNMSM estan empezando a utilizar la herramienta de aula virtual Moodle, por lo que se puede afirmar que, ya despegaron en el uso de las herramientas de aprendizaje a distancia o e-Learning.

\section{REFERENCIAS BIBLIOGRÁFICAS}

1. BAÑOS, S. (2007) La Plataforma educativa Moodle. [fecha de consulta: 4 setiembre 2015] Disponible en: http://www.fvet.uba.ar/postgrado/Moodle18_Manual_Prof_1.pdf
2. MUNDAY, P. (2004) Educación a distancia a través de AVE on JSTOR. [fecha de consulta: 22 agosto 2015] Disponible en: http://www.jstor.org/ stable $/ 20140907$ ? Search=yes\&resultItemClick=true\&searchText=aula\&searchText=virtual\&searchUri=/action/doBasicSearch?Query=aula+virtual\&amp; $\mathrm{acc}=\mathrm{on} \& \mathrm{amp} ; \mathrm{wc}=\mathrm{on} \& \mathrm{amp} ; \mathrm{fc}=\mathrm{o}$ ff\&amp;group $=$ none\&seq $=1$ \#page_scan_tab

3. RODRIGUEZ, A. (2005) Persona ética y organización: Hacia un nuevo paradigma organizacional.: EBSCOhost. [fecha de consulta: 30 julio 2015] Disponible en: http://eds.a.ebscohost. com/ehost/pdfviewer/pdfviewer?sid=2070338 d-f6c1-4449-bba8-9a8629ee0b81\%40sessionmgr4001\&vid $=1$ \&hid $=4102$

4. SANTIBÁÑEZ (2010) Aula virtual y presencial en aprendizaje de comunicación audiovisual y educación/ Virtual and Real Classroom in Learning Audiovisual Communication and Education - ProQuest. [fecha de consulta: 28 agosto 2015] Disponible en: http://search.proquest.com/ docview/757727332/B703B01B41A44E3PQ/9? accountid $=12268$

5. SILVA, J. (2011). Guía de trabajo recursos y actividades Moodle 2011. [fecha de consulta: 20 agosto 2015] Disponible en: http://educa2014. uct.cl/file.php/1/Biblioteca/moodle/manuales/ Profesor_editor_2011.pdf

6. TORRAS, A. (2013) El aprendizaje colaborativo en línea y la ética del cuidado: EBSCO host.[fecha de consulta: 30 agosto 2015]Disponible en: http://eds.a.ebscohost.com/ehost/pdfviewer/pdfviewer?si$\mathrm{d}=\mathrm{e} 3 \mathrm{~d} 84 \mathrm{~b} 3 \mathrm{c}-94 \mathrm{~d} 4-4208-9 \mathrm{c} 36-789 \mathrm{~d} 94 \mathrm{feb}-$ b8a\%40sessionmgr4001\&vid $=1$ \&hid $=4102$

7. UNMSM (2013) Modelo Educativo 2013_para Vicerrectorado.pdf. [fecha de consulta: 20 agosto 2015] Disponible en: http://viceacademico.unmsm.edu.pe/archivos/MODELO EDUCATIVO 2013_para_Vicerrectorado.pdf 